\title{
ANALISIS PERHITUNGAN NILAI TAMBAH PADA AGROINDUSTRI STROBERI \\ (Studi Kasus Pada Pelaku Usaha Di Desa Pandanrejo, Kecamatan Bumiaji, Kota Batu)
}

\author{
Erlin Widya Fatmawati \\ Program Studi Agribisnis, Fakultas Pertanian \\ Universitas Islam Kadiri, Kediri \\ Email : erlin.widyaf@gmail.com
}

\begin{abstract}
This study examines the value added strawberries are processed into food that is more economical. This research is important because one of the obstacles faced by entrepreneurs in selling strawberries, the fruit is easily damaged. The purpose of this reseach was describe the characteristics of entrepreneurs agro-industry and agroindustry to analyze value added strawberries. Doing agroindustrial strawberries means providing added value to the products processed strawberries oriented higher selling prices. With the processing of strawberries, is expected to provide additional revenue businesses. By using the analysis of the value added by Metode of Hayami, it can be concluded that the three preparations of strawberries, namely dodol strawberries, strawberry jam and strawberry juice, which has the highest added value is the strawberry juice.
\end{abstract}

Keywords: strawberries, Value added

\section{PENDAHULUAN}

Beberapa hal menyebabkan hasil-hasil produk pertanian akan kalah bersaing dengan produk-produk impor dari Negara lain. Penyebabnya antara lain produk pertanian yang mudah rusak, kurangnya penanganan pasca panen, panjangnya saluran pemasaran yang ada di Indonesia, masalah kelembagaan dan lain sebagainya. Adapun strategi yang dapat dilakukan oleh para petani sebagai pelaku usaha adalah melakukan pengolahan pasca panen, atau bisa disebut dengan melakukan agroindustri. Agroindustri merupakan kegiatan yang memanfaatkan hasil pertanian primer sebagai bahan baku utama dengan jumlah minimal 20\% dari jumlah bahan baku yang digunakan. Udayana (2011) menjelaskan mengenai agroindustri dimana industry ini merupakan kegiatan yang memanfaatkan hasil pertanian primer sebagai bahan baku utamanya atau kegiatan industri yang menciptakan produk olahan yang dimanfaatkan sebagai sarana produksi atau input dalam usaha tani. Kegiatan agroindustri memberikan dampak positif terhadap pendapatan rumah tangga petani sebagai pelaku usaha. Agroindustri memberikan tambahan masukan pendapatan rumah tangga petani sebagai pelaku usaha, karena produk olahan agroindustri memiliki nilai jual produk olahan yang lebih tinggi dibandingkan nilai jual produk mentah.

Buah stroberi merupakan salah satu produk potenisal di Indonesia, namun memiliki karakteristik buah yang mudah rusak. Salah satu sentra penghasil stroberi dan menjadi kawasan wisata petik buah stroberi adalah Desa Pandanrejo, Bumiaji, Batu. Beberapa pelaku usaha disini telah melakukan agroindustri buah stroberi menjadi dodol stroberi, sari buah stroberi, selai stroberi, stik stroberi dan lainnya. Namun dari berbagai olahan stroberi yang dihasilkan belum diketahui produk olahan manakah yang memiliki nilai 
tambah yang paling tinggi, dan memiliki nilai jual yang tinggi. Berdasarkan permasalahan diatas, maka dirumuskan pertanyaan penelitian sebagai berikut:

1. Bagaimana karakteristik responden pelaku usaha / agroindustri di Desa Pandanrejo, Bumiaji, Batu?

2. Bagaimana perbandingan nilai tambah dari produk olahan stroberi, yaitu dodol stroberi, sari stroberi, dan selai stroberi di Desa Pandanrejo, Bumiaji, Batu?

\section{TINJAUAN PUSTAKA}

Hayamiet,al., 1987 mendefiniskan bahwa "nilai tambah (value added) adalah upaya pelaku usaha dalam memberikan tambahan nilai pada hasil pertanian karena telah melalui berbagai proses pengolahan produk, distribusi ataupun proses simpan (gudang) dalam proses produksi tersebut. Pada kegiatan di proses pengolahan produk, proses pemberian nilai tambah dapat diartikan sebagai pengurangan antara nilai produk olahan dengan nilai biaya bahan baku dan input lainnya yang digunakan, namun nilai tenaga kerjatidakdimasukkan. Sedangkan, marjin jasa merupakan pengurangan antara nilai produk olahan dengan harga bahan bakunya saja. Dalam marjin ini mencakup antara lain seluruh sarana produksi yang digunakan yaitu biaya pekerja, input tambahan lainnya dan balas jasa pelaku usaha".

Soekartawi, 1999 menjelaskan mengenai pengolahan hasil komoditas pertanian, pemberian nilai tambah memiliki nilai ekonomis yang jauh lebih besar dibandingkan dengan produk pertanian yang dijual dalam bentuk primer (mentah). Selainitu, pengolahan hasil pertanian maupun jasa penunjang dapat memberikan dampak terhadap peningkatkan pendapatan pelaku usaha, menciptakan lapangan kerja, meningkatkan devisa negara, dan dapat menjadi faktor pendukung dalam menumbuhkan industri yang lainnya.

Bagian dalam agroindustri menjadi penting karena mempertimbangkan hal-hal sebagai berikut; Perningkatkan nilai tambah, Kualitas Hasil, Penyerapan tenaga kerja, Meningkatkan keterampilan, dan Peningkatan pendapatan.

Soekartawi (1999), mendefinisikan "nilai tambah atau value added adalah kegiatan pemberian nilai pada hasil pertanian agar lebih meningkat karena terdapat input fungsional yang dibutuhkan pada komoditas yang diberikan perlakuan. Terdapat dua faktor yang berpengaruh pada besarnya peningkatan nilai tambah yaitu faktor teknis yang terdiri dari kuantitas produksi, penggunaan teknologi, kualitas produk olahan, jumlah bahan baku atau input dan input tambahan lainya, serta faktor market yang terdiri dari harga jual produk olahan, harga bahan baku yang digunakan, jumlah nilai input tambahan dan gaji pekerja".

Sutalaksana, DM, 1993 menjelaskan bahwa agroindustri ini didasarkan pada kegiatan pengolahan yang beranekaragam, mulai dari tahap prosesnya hingga kepemasaran kepada konsumen. Penjabaran mengenai agroindustri adalah sebagai bahan baku lainnya untuk diolah dengan proses yang cukup panjang sehingga menjadi suatu produk yang unik, baik itu produk setengah jadi maupun akhir untuk dikonsumsi.

\section{METODE PENELITIAN}

Lokasi penelitian ditentukan dengan melakukan pertimbangan agar tujuan penelitian tercapai (purposive). Karena daerah tersebut merupakan sentra kawasan usaha tani buah stroberi di Kota Batu. Besarnya sampel dilakukan secara sensus karena mengambil seluruhnya dari populasi. Dalam penelitian ini diambil 30 petani sebagai pelaku usaha yang melakukan agroindustri stroberi. 
Erlin Widya Fatmawati, 2020. Analis perhitungan Nilai Tambah Pada Agroindustri Stroberi (Studi Kasus Pada Pelaku Usaha Di Desa Pandanrejo, Kecamatan Bumiaji, Kota Batu) Journal Viabel Pertanian. (2020), 14(1)1-7

\section{Analisis Deskriptif Pelaku Usaha / Agroindustri}

Analisa deskriptif dalam penelitian ini menggunakanan alisis deskriptif karakteristik pelaku usaha agroindustri stroberi. Analisis dalam penelitian ini dapat dihubungkan dengan kemampuan atau keahlian pelaku usaha dalam menjalankan usahanya dan melihat ketersediaan modal, serta wilayah pemasaran.

\section{Analisis Nilai Tambah Buah Stroberi}

Analisis nilai tambah bertujuan untuk menghitung jumlah nilai tambah agroindustri dari masing-masing olahan. Dari berbagai olahan, akan dibandingkan 3 olahan yaitu dodol stroberi, selai stroberi, dan sari buah stroberi, dengan alas an bahwa ketiga olahan tersebut merupakan olahan yang paling diminati oleh konsumen. Analisis nilai tambah dihitung sebagai berikut:

Tabel 1. Perhitungan Value Added Nilai Tambah (Hayami,et.al.)

\begin{tabular}{|c|c|}
\hline Keterangan & Notasi \\
\hline \multicolumn{2}{|c|}{ A. OutputProdukOlahan, Input dan Price } \\
\hline 1.Produk Olahan $(\mathrm{kg})$ & (A) \\
\hline 2.Bahan Baku Primer $(\mathrm{kg})$ & (B) \\
\hline 3.Tenaga Kerja (HOK) & (C) \\
\hline 4.Faktor Konversi & $(\mathrm{D}=\mathrm{A}: \mathrm{B})$ \\
\hline 5.Koefisien TenagaKerja (JKO/kg) & $(\mathrm{E}=\mathrm{C}: \mathrm{B})$ \\
\hline 6.Harga Produk Olahan (Rp/unit) & $(\mathrm{F})$ \\
\hline 7.Gaji Tenaga Kerja(Rp/JKO) & (G) \\
\hline \multicolumn{2}{|l|}{ B. Revenue dan Profit } \\
\hline 8.Harga Bahan Baku $(\mathrm{Rp} / \mathrm{kg})$ & $(\mathrm{H})$ \\
\hline 9.Tambahan Input Lain (Rp/kg) & (I) \\
\hline 10.Nilai Produk Olahan $(\mathrm{Rp} / \mathrm{kg})$ & $(\mathrm{J}=\mathrm{D} \times \mathrm{F})$ \\
\hline 11. a.Value Added (Rp/kg) & $(\mathrm{K}=\mathrm{J}-\mathrm{H}-\mathrm{I})$ \\
\hline b.Rasio Value Added (\%) & {$[\mathrm{I} \%=(\mathrm{K}: \mathrm{J}) \%]$} \\
\hline 12.a.Pendapatan Pekerja $(\mathrm{Rp} / \mathrm{kg})$ & $(\mathrm{M}=\mathrm{E} \times \mathrm{G})$ \\
\hline b.Pangsa Pekerja (\%) & {$[\mathrm{N}=(\mathrm{M}: \mathrm{K}) \%]$} \\
\hline 13.a.Keuntungan $(\mathrm{Rp} / \mathrm{kg})$ & $(\mathrm{O}=\mathrm{K}-\mathrm{M})$ \\
\hline b.Profit(\%) & {$[\mathrm{P}=(\mathrm{O}: \mathrm{K}) \%]$} \\
\hline \multicolumn{2}{|c|}{ C. Pemberian Jasa Untuk Faktor Produksi } \\
\hline 14.Marjin $(\mathrm{Rp} / \mathrm{kg})$ & $(\mathrm{Q}=\mathrm{J}-\mathrm{H})$ \\
\hline a. PendapatanPekerja (\%) & {$[\mathrm{R}=(\mathrm{M}: \mathrm{Q}) \%]$} \\
\hline b.Tambahan Input Lain (\%) & {$[\mathrm{S}=(\mathrm{I}: \mathrm{Q}) \%]$} \\
\hline c. ProfitPelaku (\%) & {$[\mathrm{T}=(\mathrm{O}: \mathrm{Q}) \%] \mathrm{S}$} \\
\hline
\end{tabular}




\section{HASIL DAN PEMBAHASAN}

\section{Karakteristik Pelaku Usaha / Agroindustri Stroberi \\ Usia Responden}

Usia responden dapat dijadikan salah satu faktor yang mempengaruhi petani sebagai pelaku usaha dalam mengelola usaha tani yang dilakukan, terutama dalam hal kemampuan fisik dan pengambilan keputusan dalam penerapan adopsi inovasi. Saat usia berada pada kategori produktif, kemampuan fisik petani sebagai pelaku usaha untuk bekerja cenderung lebih optimal dibandingkan usia tidak produktif. Seseorang yang memiliki umur produktif cenderung lebih semangat untuk belajar hal baru, sehingga cenderung lebih mudah menerima inovasi, sebaliknya seseorang pada umur tidak produktif akan lebih sulit menerima adopsi inovasi (Prabayanti, 2010).

Tabel 2. Persentase Usia Pelaku Usaha Agroindustri Stroberi di Ds. Pandanrejo, Bumiaji, Kota Batu Tahun 2018.

\begin{tabular}{|c|c|c|c|}
\hline No & $\begin{array}{c}\text { Kelompok Usia } \\
\text { (Tahun) }\end{array}$ & Jumlah (orang) & Persentase(\%) \\
\hline 1 & $21-31$ & 0 & 0 \\
\hline 2 & $31-41$ & 3 & 10 \\
\hline 3 & $41-51$ & 7 & 23.3 \\
\hline 4 & $51-61$ & 13 & 43.4 \\
\hline 5 & $61-71$ & 7 & 23.3 \\
\hline \multicolumn{2}{|r|}{ Jumlah } & 30 & 100 \\
\hline
\end{tabular}

(Sumber data primer yang telah diolah, 2018)

Pelaku usaha agroindustri stroberi dengan persentase tertinggi berada pada kelompok usia 51-61 tahun, dan persentase terendah berada pada kelompok usia 21-41 tahun. Hal ini menunjukkan bahwa para pemuda- peuda di daerah penelitian tidak banyak yang berminat dalam bidang pengolahan agroindustri stroberi.

\section{Tingkat Pendidikan Responden}

Tingkat pendidikan petani sebagai pelaku usaha terdiri dari Sekolah Dasar, Sekolah Menengah Pertama, Sekolah Menengah Atas, dan Strata 1/Sederajat.

Tabel 3. Persentase Tingkat Pendidikan Pelaku Usaha Agroindustri Stroberi di Ds. Pandanrejo, Bumiaji, Kota Batu Tahun 2018.

\begin{tabular}{|c|l|c|c|}
\hline No & $\begin{array}{c}\text { Tingkat Pendidikan } \\
\text { Pelaku }\end{array}$ & Jumlah (orang) & Persentase (\%) \\
\hline 1 & SD Sederajat & 4 & 13,3 \\
\hline 2 & SMP Sederajat & 18 & 60 \\
\hline 3 & SMA Sederajat & 7 & 23,3 \\
\hline 4 & S-1 Jumlah & 1 & 3 \\
\hline \multicolumn{2}{|c|}{ Jum } \\
\hline
\end{tabular}

(Sumber data primer yang telah diolah, 2018)

Pelaku usaha agroindustri memiliki persentase paling tinggi berada pada tingkat SMP yaitu sebesar $60 \%$ dan terendah adalah S-1 sebesar 3\%. Melakukan pengolahan stroberi menjadi bahan makanan yang beranekaragam membutuhkan ketrampilan yang tinggi. Oleh karena itu meskipun banyak yang berpendidikan cukup rendah (SMP), namun mereka sering mendapatkan pelatihan dari penyuluh setempat. 


\section{Luas Lahan Responden}

Lahan merupakan potensi ekonomi petani sebagai salah satu sarana produksi untuk berusaha tani stroberi. Luas lahan yang disajikan dalam tabel dibawah ini adalah luas lahan yang dimanfaatkan petani untuk melakukan budidaya buah stroberi.

Tabel 4. Persentase Luas Lahan Pelaku Usaha Agroindustri Stroberi di Ds. Pandanrejo, Bumiaji, Kota Batu Tahun 2018.

\begin{tabular}{|c|c|c|c|}
\hline No & Luas Lahan $\left.\mathbf{( m}^{\mathbf{2}}\right)$ & Jumlah (orang) & Persentase (\%) \\
\hline 1 & $300-1533$ & 20 & 66.7 \\
\hline 2 & $1533-2767$ & 4 & 13.3 \\
\hline 3 & $2767-4000$ & 6 & 20 \\
\hline & Jumlah & 30 & 100 \\
\hline
\end{tabular}

(Sumber data primer yang telah diolah, 2018)

Berdasarkan tabel d iatas, pelaku usaha agroindustri stroberi sebagian besar memiliki lahan sekitar $300-1533 \mathrm{~m}^{2}$. Dapat disimpulkan bahwa luas lahan stroberi yang dimiliki cukup sempit dan hasil stroberi mereka juga sedikit, sehingga dilakukan pengolahan agroindustri stroberi dengan tambahan bahan baku yang lainnya agar produk stroberi lebih bernilai ekonomis.

\section{Jumlah Anggota Keluarga Pelaku Usaha Agroindustri}

Jumlah anggota keluarga adalah jumlah seluruh anggota keluarga yang ikut dan hidup bersama-sama dalam satu atap rumah, meliputi suami/istri, anak, maupun anggota keluarga lainnya yang hidup di dalam satu rumah dengan petani sebagai pelaku usaha. Tabel 5. Persentase Jumlah Anggota Keluarga Pelaku Usaha Agroindustri Stroberi di Ds. Pandanrejo, Bumiaji, Kota BatuTahun 2018.

\begin{tabular}{|c|c|c|c|}
\hline No & $\begin{array}{c}\text { Jumlah Anggota } \\
\text { Keluarga }\end{array}$ & Jumlah (orang) & Persentase (\%) \\
\hline 1 & $1-3$ & 12 & 40 \\
\hline 2 & $3-5$ & 15 & 50 \\
\hline 3 & $5-7$ & 3 & 10 \\
\hline \multicolumn{2}{|c|}{ Jumlah } & 30 & 100 \\
\hline
\end{tabular}

(Sumber data primer yang telah diolah, 2018)

Berdasarkan data tabel di atas, pelaku usaha agroindustri memiliki jumlah keluarga terbanyak sekitar 3-5 orang. Jumlah tersebut cukup ideal dalam suatu keluarga, sehingga diharapkan anggota-anggota dalam keluarga dapat memberikan kontribusinya dalam pengolahan agroindustri stroberi.

Tabel 6. Persentase Modal Pelaku Usaha Agroindustri Stroberi di Ds. Pandanrejo,

Bumiaji, Kota Batu.

\begin{tabular}{|c|c|c|c|}
\hline No & \multicolumn{1}{|c|}{ Modal } & Jumlah Responden & Persentase \\
\hline 1 & $<5.000 .000,-$ & 11 & 36,7 \\
\hline 2 & $5.000 .000,--7.500 .000,-$ & 7 & 23,3 \\
\hline 3 & $7.500 .000,--10.000 .000,-$ & 10 & 33,3 \\
\hline 4 & $10.000 .000,--12.500 .000,-$ & 2 & 6,7 \\
\hline 5 & $>12.500 .000,-$ & 0 & 0 \\
\hline \multicolumn{2}{c|}{ Jumlah } & 30 & 100 \\
\hline
\end{tabular}

(Sumber data primer yang telah diolah, 2018)

Berdasarkan data di atas, dapat disimpulkan bahwa modal yang digunakan oleh pelaku usaha agroindustri stroberi relaatif kecil yaitu antara 5.000.000 - 7.500.000. hal ini menunjukkan bahwa pelaku usaha belum berani mengambil resiko dengan memperbesar 
Erlin Widya Fatmawati, 2020. Analis perhitungan Nilai Tambah Pada Agroindustri Stroberi (Studi

Kasus Pada Pelaku Usaha Di Desa Pandanrejo, Kecamatan Bumiaji, Kota Batu) Journal Viabel Pertanian. (2020), 14(1)1-7

usahanya lewat penambahan modal. Rata-rata usaha yang dilakukan masih berupa usaha skala rumah tangga yang kecil.

Tabel 7. Persentase Wilayah Pemasaran Pelaku Usaha Agroindustri Stroberi di Ds.

Pandanrejo, Bumiaji, Kota Batu.

\begin{tabular}{|c|l|c|c|}
\hline No & \multicolumn{1}{|c|}{ Pemasaran } & Jumlah Responden & Presenteasi \\
\hline 1 & Dalam Kota (Batu) & 18 & 60 \\
\hline 2 & Luar Kota (Malang, Surabaya) & 2 & 6,7 \\
\hline 3 & Dalam Kota dan Luar Kota & 10 & 33,3 \\
\hline \multicolumn{2}{|c|}{ Jumlah } & 30 & 100 \\
\hline
\end{tabular}

(Sumber data primer yang telahdiolah, 2018)

Dari tabel, cakupan wilayah pemasaran pelaku usaha agroindustri stroberi dengan persentase terbesar hanya dalam kota atau di wilayah Batu saja. Hal ini dikarenakan Batu merupakan daerah wisata yang sering dikunjungi oleh masyarakat. Jadi, persediaan selalu habis untuk dijual di wilayah Batu.

\section{Nilai Tambah}

Berikut adalah tabel rincian nilai tambah dari ketiga olahan agroindustri stroberi, yaitu sari buah stroberi, selai stroberi, dan dodol stroberi.

Tabel 8. Rincian Nilai Tambah Masing-Masing Olahan Agroindustri Stroberi.

\begin{tabular}{|c|c|c|c|}
\hline \multirow[t]{2}{*}{ Variabel } & \multicolumn{3}{|c|}{ NilaiTambah } \\
\hline & Sari Stroberi & Selai Stroberi & Dodol stroberi \\
\hline \multicolumn{4}{|l|}{ Output, input dan harga } \\
\hline 1.Produk Olahan Stoberi (unit) & 94 cup & 26 cup & 60 unit \\
\hline 2.Stoberi Mentah $(\mathrm{kg})$ & 3 & $6 \mathrm{~kg}$ & 6 \\
\hline 3.Tenaga Kerja (HOK) & 1,0 & 2,0 & 2,0 \\
\hline 4.Faktor Konversi & 31,3 & 4,3 & 10 \\
\hline 5.Koefisien Tenaga Kerja (JKO/kg) & 0,3 & 0,3 & 0,5 \\
\hline 6.Harga Olahan (Rp/unit) & Rp. 3000,- /cup & Rp.15.000,-/cup & Rp. 8.000,- /unit \\
\hline 7.Upah TK (Rp/JKO) & R. 9195,- & Rp. 5.188,- & Rp. 5362,- \\
\hline \multicolumn{4}{|l|}{ Penerimaan dan Keuntungan } \\
\hline 8.Harga Bahan Baku (Rp/kg) & Rp. 25.000,-/kg & Rp. 25.000,-/kg & Rp.25.000,-/kg \\
\hline 9.Tambahan Bahan lainnya (Rp/kg) & $48.450,-$ & $34.375,-$ & $42.797,-$ \\
\hline 10.Nilai Olahan $(\mathrm{Rp} / \mathrm{kg})$ & 93.900,- & $65.000,-$ & $80.000,-$ \\
\hline 11. a.Nilai Tambah $(\mathrm{Rp} / \mathrm{kg})$ & $20.450,-$ & $5.625,-$ & $12.203,-$ \\
\hline b.Rasio Nilai Tambah (\%) & 21,77 & 8,65 & 15,25 \\
\hline 12.a.Pendapatan Tenaga Kerja (Rp/kg) & $2.758,-$ & $1.556,-$ & $2.681,-$ \\
\hline b. Pangsa Tenaga Kerja (\%) & 13,48 & 27,66 & 21,97 \\
\hline 13.a.Keuntungan (Rp/kg) & $17.692,-$ & $4.069,-$ & $9.522,-$ \\
\hline b.Tingkat Keuntungan (\%) & 86,51 & 72,33 & 78,02 \\
\hline \multicolumn{4}{|l|}{ Balas Jasa Pelaku Sarana Produksi } \\
\hline 14.Marjin (Rp/kg) & $68.900,-$ & $40.000,-$ & $55.000,-$ \\
\hline a.Pendapatan tenaga kerja $(\%)$ & 4,00 & 3,89 & 4,87 \\
\hline b.Pendapatan Input Lain (\%) & 70,31 & 85,93 & 77,81 \\
\hline c.Keuntungan pelaku (\%) & 25,67 & 10,17 & 17,31 \\
\hline
\end{tabular}

Berdasarkan hasil analisis nilai tambah diatas, bahwa olahan sari buah stroberi memiliki hasil nilai tambah yang paling tinggi yaitu Rp. 20.450,- / kg, sedangkan olahan selai stroberi memiliki nilai tambah yang paling rendah, yaitu Rp. 5.625,- / kg. Hal ini dikarenakan olahan sari buah stroberi lebih mudah diproses dan tidak membutuhkan bahan baku tambahan yang banyak. Apabila dilihat dari tingkat keuntungan pengusaha, 
olahan sari buah stroberi memiliki tingkat keuntungan paling tinggi, yaitu 25,67\% dibandingkan dengan selai stroberi dan dodol stroberi. Hal ini dikarenakan proses pembuatan sari buah stroberi tidak membutuhkan bahan baku tambahan yang banyak dan tenaga kerja yang diperlukan sedikit karena dalam pembuatannya banyak menggunakan mesin.

\section{KESIMPULAN}

1. Karakteristik pelaku usaha agroindustri stroberi memiliki usia rata-rata 51-61 tahun dengan latar belakang pendidikan rata-rata adalah SMP. Luas lahan stroberi yang dimiliki pelaku usaha hanya sekitar $300-1533 \mathrm{~m}^{2}$, masih relatif sempit. Jumlah anggota keluarga yang dimiliki rata-rata 3-5 orang, termasuk ideal dalam sebuah keluarga. Namun modal yang digunakan oleh pelaku usaha relatif kecil hanya sekitar 5.000.000,- - 7.500.000,- dengan cakupan wilayah pemasaran hanya di dalam kota (Batu) saja. Hal tersebut membuat agroindustri stroberi kurang berkembang menjadi skala yang lebih luas dan lebih besar.

2. Sari buah stroberi memiliki tingkat keuntungan paling tinggi, yaitu $25,67 \%$ dibandingkan dengan selai stroberi dan dodol stroberi. Hal ini dikarenakan proses pembuatan sari buah stroberi tidak membutuhkan bahan baku tambahan yang cukupbanyak dan pekerja yang diperlukan sedikit karena dalam pembuatannya banyak menggunakan mesin.

\section{SARAN}

Terdapat saran untuk hasil penelitian ini adalah:

1. Upaya peningkatan pendapatan rumah tangga pelaku usaha stroberi dapat dilakukan dengan melakukan pengembangan agroindustri stroberi, dengan cara menambah berbagai olahan stroberi agar lebih bervariatif dan memiliki nilai tambah untuk produk olahan yang tinggi.

\section{DAFTAR PUSTAKA}

Hayami Y.,et. all.. 1987. "Agricultural Markerting and Processing in Upland Java: A prospectif From A Sunda Village". Bogor

Soekartawi. 1999.” Agribisnis Teori dan Aplikasinya”. Raja Grafindo Persada. Jakarta.

Sutalaksana, DM, 1993.’Permodalan Pengembangan Agroindustri Besar Menengah dan Kecil, Bangkit". Jakarta.

Rizal. Mochamad. 2012.” Analisis Nilai Tambah Agroindustri Tempe Di Kelurahan Medokan Ayu Kota Surabaya" . Fakultas Pertanian. UPN Veteran. Surabaya.

Udayana, 2011.“Peran Agroindustri dalam Pembangunan Pertanian”.Singhadwala 